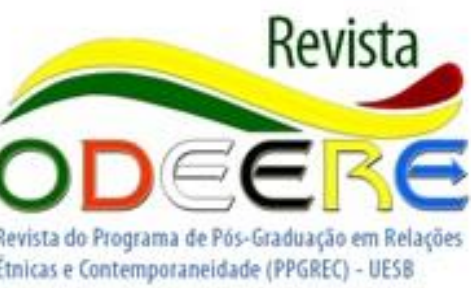

\title{
Gênese do racismo no processo migratório brasileiro
}

\section{Genesis of racism in the Brazilian migration process}

\section{Claudia de Faria Barbosa}

http://orcid.org/0000-0002-4905-9797 Universidade Estadual do Sudoeste da Bahia \& Centro Universitário UniRuy barbosa.claudiadefariabarbosa@gmail.com

\section{Clodoaldo Silva da Anunciação}

https://orcid.org/0000-0002-6264-7235 Universidade Estadual de Santa Cruz (UESC) csa_silva@hotmail.com

\section{DOI: 10.22481/odeere.v5i10.7467}

RESUMO: Situações históricas produzem(iram) marcas físicas e/ou emocionais significativas na vida das pessoas que vivem(ram) no Brasil, causando desequilíbrios em toda a sociedade, com problemas sérios de convivência, sobretudo no que tange ao racismo estrutural. Com base nisso, esse estudo parte da seguinte questão geradora: considerando o Brasil um país composto por migrantes de diversas raças/etnias, por que prevalece o racismo? Para tanto possui como objetivo geral analisar a gênese do racismo a partir dos processos migratórios, especificamente, discutir legislações, mitos e costumes para compreensão do processo de racismo à brasileira que coaduna com a intenção de seu combate, analisar as situações históricas de controle de "uns" sobre os "outros" inventariados nos encontros coloniais. Trata-se de uma revisão de literatura dissertativa e configura-se como uma pesquisa exploratória. Constata-se que a gênese do racismo, subjacente às legislações, mitos e costumes pretéritos, continua a se reproduzir. Portanto, é fundamental epistemologias descolonizadoras, educação no sentido da inclusão, pertença nas representações e construções de identidades para pôr fim ao racismo estrutural e à brasileira.

PALAVRAS-CHAVE: Racismo; Migrações; Epistemologias Descolonizadoras.

ABSTRACT: Historical situations produce (iran) significant physical and / or emotional marks in the lives of people living (ram) in Brazil, causing imbalances in the whole society, with serious problems of coexistence, especially with regard to structural racism. Based on this, this study starts from the following generating question: considering Brazil a country composed of migrants of different races / ethnicities, why does racism prevail? For this purpose, its general objective is to analyze the genesis of racism based on migratory processes, specifically, to discuss laws, myths and customs to understand the Brazilian racism process that is consistent with the intention of combating it, to analyze the historical situations of control of "some" over the "others" inventoried in colonial meetings. This is a review of the literature, configured as an exploratory research. It appears that the genesis of racism, which underlies past laws, myths and customs, continues to reproduce. Therefore, decolonizing epistemologies, education in the sense of inclusion, belonging to representations and constructions of identities are essential to end structural and Brazilian racism.

KEYWORDS: Racism; Migrations; Decolonizing Epistemologies. 
Pode o subalterno falar? Spivak, 2010

\section{Introdução}

A primeira parte deste texto aborda as questões históricas, sociais, econômicas e culturais do Brasil que são fundamentais para a compreensão do processo de divisão que culminou em situações não somente discriminatórias étnico raciais, mas sobretudo racistas. Na segunda são expostas as discussões no que tange aos legados racistas deixados pela colonização e a necessidade de mudanças culturais, que coadunam com uma política migratória que impeça a violação de direitos, considerando a prerrogativa de fim das discriminações étnicoraciais e do racismo para a concretização de Direitos Humanos.

Conforme Nascimento e Pereira' não se pode conceber uma educação, na qual os saberes de grupos e etnias europeias foram tidos como superiores. "Tratase de um saber-intervenção que cumpria um objetivo estratégico no processo de dominação colonial: conhecer para melhor dominar". Nesse sentido, considerando os grupos étnicos presentes na formação da sociedade brasileira há de olhar criticamente para as políticas ultramarinas europeias e investir em políticas públicas e ações com propostas de vanguarda e pertença com fins de aproximações e acolhimento de todos os povos, considerando a dignidade da pessoa humana em sua plenitude, com o fim do racismo.

\section{Dualidades excludentes: breve percurso histórico}

Partindo do pressuposto de que o racismo é um fundamento estruturador das relações, o seu conceito com base na teoria crítica racial, colonialismo, imperialismo e capitalismo ajudam a compreender porque ele ganhou forças e dimensões estruturais. Racismo é uma forma sistemática de "discriminação que tem a raça como fundamento, e que se manifesta por meio de práticas conscientes ou inconscientes que culminam em desvantagens ou privilégios, a

\footnotetext{
1 NASCIMENTO, W. e PEREIRA, M. S. Desafios de Pesquisar os "Outros" em Contextos Coloniais Africanos. In: Santana, M.; Ferreira, E.; Nascimento, W. Luanda \& Bahia: identidades e etnicidades em contextos contemporâneos. Campinas, SP: Pontes Editores, 2020, p. 17.
} 
depender ao grupo racial ao qual pertençam"2, o racismo estrutural vai além, não somente da dimensão interpessoal, mas abrange as instituições. Nesse sentido, refere-se a um processo histórico, econômico, político e social que forja condições sociais para que pessoas e grupos sejam discriminados de forma sistemática, seja direta ou indiretamente 3 .

Há uma dicotomia histórica essencial no país que o divide de forma maniqueísta, tendo uma parte boa e outra ruim, considerando aspectos geográficos (norte e sul) e principalmente étnicos (brancos, negros e índios). Isso está subjacente às ações, tanto das pessoas, como das instituições, como discutese na sequência.

O então presidente da Comissão Europeia, José Manuel Durão Barroso4e5 (2011), afirmou que o Brasil é considerado como uma potência pelos países europeus e corresponsável pelo enfrentamento das crises econômicas globais. Ele tratava do mito do Brasil como um novo "eldorado" da economia mundial instigando um aprofundamento sobre a temática. Do que ele falava exatamente?

Em uma ilustração dessa dicotomia tem-se o legado de Nina Rodrigueśb. Embora mulato, o cientista foi influenciado pelas escolas criminológicas italiana ${ }^{7} \mathrm{e}$ francesa da sua época e na intensa biologização do mundo com reflexo nas suas obras, que embasaram posições políticas e sociais discriminatórias. ${ }^{8}$ Vê, de um lado, um Brasil arcaico, pobre, sem perspectivas de progresso, onde predominavam os negros e mulatos; de outro, um Brasil moderno, rico ou mais rico,

\footnotetext{
${ }_{2}$ ALMEIDA, Silvio Luiz de. O que é racismo estrutural? Belo Horizonte (MG): Letramento, 2018, p.25.

3 Ibidem

${ }^{4}$ AGÊNCIA BRASIL. Europeus consideram Brasil uma potência, diz Durão Barroso. Reportagem de Renata Giraldi. Disponível em: http://agenciabrasil.ebc.com.br/noticia/2011-10-04/europeusconsideram-brasil-uma-potencia-diz-durao-barroso. Acesso em 05 set. 2020.

5 O Centro em Rede de Investigação em Antropologia (CRIA) e Instituto de Ciências Sociais (ICS/ISCTE) desenvolveram o projeto "Travessias do Atlântico: materialidade, movimentos contemporâneos e políticas de pertença". O CRIA e ICA/ISCTE investigaram pessoas no Brasil e Portugal e constataram que os portugueses que desejam emigrar têm uma representação altamente idealizada do Brasil.

¿NINA RODRIGUES, R. de. Os Africanos no Brasil. $2^{a}$ ed. São Paulo, Nacional, 1935. Era médico, antropólogo e professor da Universidade de Medicina da Bahia.

$7 \mathrm{Na}$ teoria determinista criminológica/genética com base nos estudos de Cesare Lombroso. Seus estudos foram no campo da caracterologia e levaram a equívocos de que o caráter de uma pessoa é formado de acordo com suas características físicas, que iriam definir a psicopatologia criminal de alguém. Suas ideias surgiram a partir do respaldo teórico de ideias advindas de Herbert Spencer e Charles Darwin.

8 GOBINEAU, Joseph A. Essai sur l'inegalité des races humaines.
} 
pautado pelos ideais do progresso em decorrência das ações dos imigrantes brancos, o Brasil Meridional, um país a ser construído.

Não compartilhando exatamente dos postulados de Nina Rodrigues, mas identicando a dicotomia e segregação existente, de forma metafórica, DaMatta refere-se ao Brasil com "b" minúsculo que se trata "apenas de um objeto sem vida, autoconsciência ou pulsação interior, pedaço de coisa que morre e não tem a menor condição de se reproduzir como sistema". Essa situação expõe fragilidades de um "conjunto doentio e condenado de raças que, misturando-se ao sabor de uma natureza exuberante e de um clima tropical, estariam fadadas à degeneração e à morte psicológica e social. 9 Essa é uma das problemáticas levantadas pelo autor que podem ajudar a compreender os conflitos étnico-raciais existentes.

Esse Brasil com "b" minúsculo se revela em um "mundo vivido" marcado pela exploração dos recursos naturais e humanos sem contrapartida no avanço social e civilizacional, violências sobrepostas, pobreza, exclusão social, desigualdades acentuadas de classe, privilégios, racismo, discriminações, corrupção endêmica e dificuldade de cumprimento das leis.

DaMatta ilustra um outro Brasil com "B" maiúsculo com suas pontencialidades que "é país, cultura, local geográfico, fronteira e território reconhecidos internacionalmente, e também casa, pedaço de chão". Talvez seja essa a raiz de um problema que explode em um país continental porque "[...]de algum modo se recusa a viver de forma totalmente planificada e hegemonicamente padronizada pelo dinheiro das contas bancárias ou pelos planos quinquenais dos Ministérios encantados [...]". 10

Realizar um cotejo entre os dois "Brasis" permite entender o modelo cultural e normativo brasileiro e propor mudanças paradigmáticas que colaborem na substituição da ênfase ao aspecto da soberania nacional pelo princípio da inclusão e reconhecimento de direitos. Para tal, vale retomar em linhas gerais a formação econômica do Brasil que se constituiu sobre os pilares do genocídio do povo indígena, do trabalho de pessoas escravizadas oriundas de África, da ação do branco colonizador português e da exploração dos seus recursos por potências

\footnotetext{
9 DAMATTA, Roberto. O que faz o brasil, Brasil? Rio de Janeiro: Rocco:1986. p. 11

10 Ibidem, 1986. p. 11 e 14
} 
estrangeiras e o tardio processo de industrialização.

Em um escorço histórico, Chauíl aponta que a invasão do Brasil está na cadeia histórica do capitalismo mercantil que impulsionou as expedições em terras americanas. Ora, se do ponto de vista econômico, social e político as grandes navegações se justificam pela ideia de conquistas e pela colonização, do ponto de vista simbólico, as viagens significam para os seus protagonistas o alargamento das fronteiras do visivel e a superação das fronteiras do invisível para chegar a regiões que a tradição dizia impossíveis de serem conquistadas (como a dos antípodas) ou mortais (como a zona dos trópicos). À procura de novas mercadorias e saberes, as navegações traziam inéditos semióforos: "os países exóticos (índia, China e Japão) e um Mundo Novo, no qual se julgava existir o Paraíso Terreal, de que falam a Bíblia e os escritos medievais" 12 .

Essa visão fantástica e mitológica vem de ser corroborada pelos escritos históricos sobre as chamadas llhas Afortunadas ou llhas Bem-aventuradas, lugar abençoado, onde reinam primavera e juventude eternas e no qual seres humanos e animais convivem em paz. Nesse sentido, os mapas elaborados entre os anos 1325 e 1482 colocavam a "Insulla de Brazil" ou "Isola de Brazil" a oeste da Irlanda e ao sul dos Açores. Os fenícios as designaram com o nome "Braaz" e os monges irlandeses de "Hy Brazil". Esse mito continuou com a descrição ufanista da Carta de Pero Vaz de Caminha, acerca de uma terra afortunada e bem-aventurada descrita na comunicação ao El-Rei sobre o "achamento" do Brasil. Para analisar esse fenômeno há de se relacionar com o desenvolvimento econômico proposto e com a interpretações postas nos períodos, conforme discute-se a seguir.

\section{Formação econômica do brasil}

Freyre $^{13}$ analisa a formação econômica do Brasil através de uma aproximação com a metáfora da casa grande e senzala da qual o autor associa a origem da exagerada tendência para o sadismo, característica do brasileiro

\footnotetext{
11 CHAUI, Marilena. Brasil: Mito Fundador e Sociedade Autoritária: São Paulo: Fundação Perseu Abramo, 2000, p. 59.

12 Ibidem, 2000, p. 59.

13FREYRE, Gilberto. Casa Grande \& Senzala: formação da família brasileira sob regime da economia patriarcal. 49 ed. São Paulo: Global, 2004.
} 
branco (europeu) nascido e criado na fartura e na ausência de limites da "casagrande," na relação com índios, negros e mestiços, crescidos no ambiente de privação e exclusão semelhante ao da "senzala", cujas raízes e consequências se protraíram no tempo e marcam ainda as relações sociais, econômicas, políticas e jurídicas no Brasil.

Um exemplo dessa formação econômica sui generis ${ }^{14}$, é encontrado na segunda metade do século XVIII com a criação pelo marquês de Pombal da Companhia Geral do Comércio do Grão-Pará e Maranhão. Fundada em 1755 a companhia visava controlar e fomentar a atividade comercial e, diante da impossibilidade da escravidão indígena na região, passou a explorar e comercializar africanos, recebendo diversos privilégios reais para o mister. Até 1755 se estimava a existência de 3 mil africanos no local. De 1755 a 1777 o número chegou a 12 mil, e toda a aquisição dessa mão de obra que vinha de Cacheu, Bissau e Angola era financiada pela Companhia ${ }^{15}$.

A combinação do açúcar com a escravidão africana determinou a vida econômica do Império no Atlântico Sul e sustentou as ambições dos latifundiários e de uma ativa comunidade mercantil. ${ }^{16}$ Assim, a economia brasileira foi marcada por uma série de ciclos de crescimento da exportação apoiados em mão de obra escrava, primeiro com o pau-brasil e, em seguida, com a cana de açúcar no século XVIII.

Conforme aponta Schwarcz e Starling 17, a escravidão no Brasil foi um dos principais fenômenos de migração forçada de pessoas africanas. De tão disseminada, a instituição deixou de ser privilégio apenas de latifundiários e senhores de engenho, abrangendo outros atores, a exemplo de padres, militares, funcionários públicos, artesãos, taberneiros, comerciantes, pequenos lavradores, pobres e remediados e, até mesmo, negros libertos que conseguiam recursos para adquirir pessoas com fim de escravizá-las.

A escravidão manteve-se enraizada na América portuguesa e associada aos africanos e seus descendentes, de maneira a penetrar na sociedade colonial. Nesse sentido, a cor passou a ser um critério de status e distinção. Ademais, a posse

\footnotetext{
14SCHWARCZ, L. M. \& STARLING, H. M. Brasil: Uma Biografia. São Paulo: Schwarcz S.A., 2015, p. 728.

15 Ibidem, 2015, p. 728.

16 Ibidem, 2015, p. 101.

17 Ibidem, 2015, p. 234.
} 
de pessoas para serem escravizadas também demonstrava um sinal de prosperidade.

A abolição da escravatura pela Lei Imperial Áurea n. 3.353 (1888), foi precedida de três leis que continham antinomias com a realidade e com os resultados a ser obtidos: a Lei Eusébio de Queirós (1850), Lei do Ventre Livre (1871) e a Lei dos Sexagenários(1885).

A lei Eusébio de Queirós 581(1850), concebida em decorrência da pressão da Inglaterra, aplicava de forma unilateral o chamado "Bill Aberdeen", pôs fim ao tráfico interatlântico de africanos escravizados. A lei gerou efeitos imediatos na estrutura do tráfico africano para o Brasil, reduzindo gradativamente a entrada no país de novas pessoas com fins de serem escravizadas que foi finalizada em três anos. Entretanto, com o fim do tráfico atlântico, o tráfico interno cresceu e concentrou-se nas Províncias do Rio de Janeiro e de São Paulo, pois eram as áreas mais produtivas.

Mais uma vez, sob pressão da Inglaterra, o Brasil foi obrigado a combater o tráfico interno e utilizar a mão de obra assalariada. Isso calhou com o aumento demográfico na Europa, que estava na segunda fase da Revolução Industrial e enfrentava conflitos em torno das unificações da Itália e da Alemanha, de maneira que isso refletiu no aumento da emigração. Assim, o Brasil passou a ser um destino importante desse fluxo, utilizando-o como alternativa para a substituição da mão de obra escrava nas lavouras e também no "embranquecimento" da população pensado pelo Império.

A Lei do Ventre Livre n. 204018, também conhecida como Lei Rio Branco (1871) considerava livres todos os filhos de mulheres que foram escravizadas, nascidos a partir da data da lei no Império do Brasil, a saber:

Art. 1. - Os filhos de mulher escrava que nascerem no Império desde a data desta lei serão considerados de condição livre. $\S 1^{\circ}$ - Os ditos filhos menores ficarão em poder o sob a autoridade dos senhores de suas mães, os quais terão a obrigação de criá-los e tratá-los até a idade de oito anos completos. Chegando o filho da escrava a esta idade, o senhor da mãe terá opção, ou de receber do Estado a indenização de 600\$000, ou de utilizar-se dos serviços do menor até a idade de 21 anos completos. No primeiro caso, o Govêrno receberá o menor e lhe dará destino, em conformidade da presente lei.

18 BRASIL. Lei 2040 de 28 de setembro de 1781. Disponível em: http://www.planalto.gov.br/ccivil 03/leis/lim/lim2040.htm Acesso em 20 set. 2020. 
Fica patente que essas crianças continuavam a serem escravizadas, pois o texto previa a tutela de suas vidas pelos senhores de suas mães. Com efeito, esse paradoxo mostra a forma autoritária, desconectada com a realidade da formulação de leis no Brasil. Neste exemplo o efeito prático da lei era pífio.

De seu turno, a Lei n. 3.27019, também conhecida como Lei dos Sexagenários ou Lei Saraiva Cotejipe (1885) garantia liberdade às pessoas escravizadas com mais de 60 anos de idade. Não bastasse o fato de que os senhores registravam falsamente as pessoas escravizadas como mais jovens, a lei continha diversas contradições com a realidade, pois conforme o texto legal, os cativos tinham a obrigação de trabalhar por mais três anos a título de indenização ao proprietário. De fato, eram libertadas somente as pessoas que, por se encontrarem em idade avançadas, eram menos valorizadas. A expectativa nesse período era em torno de 1920 a $40^{21}$ anos, isso tornava a lei de efeito nulo. Além disso, os poucos que conseguiam obter o direito de liberdade estavam débeis não tinham para onde ir, nem condições socioeconômicas de sobrevivência de forma autônoma, assim, permaneceram na situação similar à de escravidão.

A conclusão é que a Lei Áurea22, ápice dessa evolução legislativa problemática, tem caráter casuístico e oportunista e, de forma mais grave, deixou de regular o "dia seguinte" à abolição da escravatura no que tange ao acesso a direitos de moradia, trabalho, educação e saúde dos "libertos", iniciando um novo ciclo que repetia os anteriores no que tange às discriminações, preconceitos, desigualdades e negação da condição de sujeito de direitos às pessoas que foram escravizadas e suas famílias.

Esses fatores demonstram que a escravidão foi mais que um sistema econômico, pois na sua essência moldou condutas, definiu desigualdades sociais,

19 BRASIL. Lei n. 3270, de 28 de setembro de 1885. Disponível em: https://www.bn.gov.br/explore/curiosidades/28-setembro-1885-promulgada-leisexagenarios. Acesso em 21 set. 2020.

20Schwartz demonstra que no Brasil do último quarto do século XIX a expectativa de vida de uma pessoa escravizada, ao nascer, variava em torno de 19 anos, enquanto a de um brasileiro não escravizado era de apenas 27 anos em 1879. SCHWARTZ, Stuart B. Segredos Internos: engenhos e escravos na sociedade colonial (1550-1835). São Paulo: Companhia das Letras, 1988.

21 SOARES, Luiz Carlos. O "povo de Cam" na capital do Brasil: A escravidão Urbana no Século XIX: Rio de Janeiro: 7 letras. 2007. O autor aponta que essa expectativa de vida era em torno de 40 anos.

22 BRASIL. Lei 3.353, de 13 de maio de 1888. Disponível em: http://www.planalto.gov.br/ccivil 03/leis/lim/LIM3353.htm Acesso em 21 set. 2020. 
fez da raça/etnia marcadores de diferenças fundantes de conflitos, ordenou etiquetas de mando e obediência e criou uma sociedade condicionada pelo paternalismo e por uma hierarquia estrita, com reflexos indeléveis no ordenamento jurídico do país.

De forma similar, Fernandes 23 analisa 0 período pós-escravatura no qual a população negra foi ignorada pela República que preferiu imigrantes brancos europeus para inserir no mercado de trabalho. Nesse sentido, os negros passam a sofrer uma sobreposição de discriminações, tanto da população branca e de outras etnias quanto de uma parte da população negra que reforça estereótipos pela condição de classe social.

\section{Pilares constitutivos: invasão, genocídio e escravidão}

A miscigenação de povos é a característica que marca a formação da sociedade brasileira, conforme registra a história. Entretanto, apesar da chegada de migrantes africanos do século XVI até o século XIX, somente o período a partir de 1875 é considerado como início do processo migratório com a vinda de imigrantes brancos de várias procedências de maneira que a pluralidade deixou de ser trinária e se tornou complexa. ${ }^{24}$

Conforme Ribeiro25, o início dessa saga remete à Institucionalização do genocídio indígena, pois a colonização portuguesa no Brasil e espanhola nas demais colônias na América foi fundamentada na bula Romanus Pontifex da lavra do papa Nicolau $\vee$ (1454). Dentre as normas do diploma legal, destaca-se a autorização para o genocídio 26 das populações negras e indígenas e das consideradas hereges. Previa também o confisco de seus bens e exploração da riqueza encontrada nos seus territórios, consagrando a união entre o mercantilismo e a evangelização forçada, demonstrados no excerto abaixo.

\footnotetext{
${ }^{23}$ FERNANDES, Florestan. A Integração do Negro à Sociedade de Classes. São Paulo, FFLCH-USP, 1964.

24 PEREIRA, João Baptista Borges. Diversidade e pluralidade: o negro na sociedade brasileira. Rev. USP, São Paulo, n. 89, maio 2011. Disponível em http://rusp.scielo.br/scielo.php?script=sci arttext\&pid=S0103-9989201 1000200019\&lng=pt\&nrm=iso . Acessos em 21 set. 2020.

25 RIBEIRO, Darcy. O Povo Brasileiro: A Formação e o Sentido do Brasil. 2 ed. São Paulo: Companhia das Letras, 1995, p. $39-40$.

26 Ibidem, 1995, p. 39 - 40.
} 
Por isso nós, tudo com devida ponderação, concedemos ao dito rei Afonso a plena e livre faculdade, entre outras, de invadir, conquistar, subjugar a quaisquer sarracenos e pagãos, inimigos de Cristo, suas terras e bens, a todos reduzir à servidão e tudo praticar em utilidade própria e dos seus descendentes. Tudo declaramos pertencer de direito in perpetuum aos mesmos D. Afonso e seus sucessores, e ao infante. Se alguém, indivíduo ou coletividade, infringir essas determinações, seja excomungado [...]. ${ }^{27}$

Mais tarde, o Vaticano promulga a bula Inter Coetera (1493), mantendo-se a concepção e doutrina da anterior no sentido de que o Novo Mundo era legitimamente possível e seus povos também poderiam ser escravizados por Espanha e Portugal, in verbis 28

E a vós e aos sobreditos herdeiros e sucessores, vos fazemos, constituímos e deputamos por senhores das mesmas, com pleno, livre e onímodo poder, autoridade e jurisdição. [...] sujeitar a vós, por favor da Divina Clemência, as terras firmes e ilhas sobreditas, e os moradores e habitantes delas, e reduzi-los à Fé Católica [...]. ${ }^{29}$

Essa ideia disseminada pela Igreja Católica ganhou forças também no Direito Internacional por meio do chamado "Direito de comunicação entre os povos", pregado por Francisco de Vitória30 que na verdade era unilateral, posto que as populações conquistadas pelos europeus não tinham os mesmos direitos e prerrogativas dos conquistadores, de maneira que o princípio foi distorcido e legitimou as ações exterminadoras tanto de portugueses quanto de espanhóis.

Essas ações dos colonizadores europeus, conforme Todorov31, provocaram

\footnotetext{
27 BULA ROMANUS PONTIFEX. Disponível em: https://ensina.rtp.pt/artigo/emissao-da-bula-romanuspontifex/ Acesso em 21 set. 2020.

${ }^{28}$ Esses fatos foram reconhecidos recentemente pelo Papa Francisco, no dia 10 de julho de 2015, quando em viagem à Bolívia pediu desculpas em nome da igreja católica nos seguintes termos: "Alguns podem dizer que quando o Papa fala de colonialismo, ele se esquece de algumas ações da lgreja. Mas eu digo isso a vocês com lamento: muitos pecados foram cometidos contra os povos latinos em nome de Deus [...]. Eu humildemente peço perdão, não apenas pelas ofensas da Igreja em si, mas também pelos crimes cometidos contra povos nativos durante a chamada conquista da América. In: O GLOBO. Papa pede desculpas a indígenas por cumplicidade da Igreja durante era colonial. Disponível em: http://oglobo.globo.com/sociedade/religiao/papa-pede-desculpasindigenas-por-cumplicidade-da-igreja-durante-era-colonial-16722556\#ixzz3yp89Y2yn. Acesso em 5 set. 2020.

29 SOARES, Luiz Carlos. O "povo de Cam" na capital do Brasil: A escravidão Urbana no Século XIX: Rio de Janeiro: 7 letras. 2007, p. 25.

30 FERRA JOLI, Luigi. A Soberania no mundo moderno. São Paulo: Martins Fontes. 2002.

31 TODOROV. Tzvetan. A conquista da América: a questão do outro. 3 ed. São Paulo: Martins Fontes, 1993.
} 
uma hecatombe humanitária com a redução da população no México que, nas vésperas da invasão, cerca do ano 1492, era de 25 milhões de pessoas e diminuiu para um milhão no ano 1600. No Brasil, a despeito dos números controversos, estima-se que em 1500 a população indígena era de 1 a 8 milhões, aproximadamente e que o "encontro" com os europeus teria dizimado entre $25 \%$ e $95 \%$ desse contingente. ${ }^{32}$

Esse holocausto no solo das Américas foi efetivado por meio de três estratégias, duas delas conscientes e uma que pode ser considerada, em parte, não proposital, a saber: os assassinatos de indígenas em guerras e massacres, a escravidão e, por último, a transmissão de doenças 33 .

Ribeiro ${ }^{34}$, ao referir-se à construção identitária no Brasil afirma que o brasileiro surge "[...] da confluência, do entrechoque e do caldeamento do invasor português com índios silvícolas e campineiros e negros africanos, uns e outros aliciados como escravos". Constata-se o inesperado resultado dessa miscigenação.

A confluência de tantas e tão variadas matrizes formadoras poderia ter resultado numa sociedade multiétnica, dilacerada pela oposição de componentes diferenciados e imiscíveis. Ocorreu justamente o contrário, uma vez que, apesar de sobreviverem na fisionomia somática e no espírito dos brasileiros os signos de sua múltipla ancestralidade, não se diferenciaram em antagônicas minorias raciais, culturais ou regionais, vinculadas a lealdades étnicas próprias e disputantes de autonomia frente à nação. ${ }^{35}$

Ocorre que, essa aparente unidade étnica não significou uniformidade em decorrência da incidência de três fatores, a saber: o ecológico imposto pelas condições de meio ambiente que forjaram adaptações regionais e configuraram a paisagem humana brasileira; o econômico, decorrente da especialização funcional, modos de produção e ordenação do capital e trabalho, com repercussão na estratificação social do país e, finalmente, a imigração, que

\footnotetext{
32SCHWARCZ, L. M. \& STARLING, H. M. Brasil: Uma Biografia. São Paulo: Editora Schwarcz S.A., 2015. 234 P.

33 SILVA FILHO, José Carlos Moreira. Da "invasão" aos sistemas penais de hoje: o discurso da inferioridade latino-americana. In: WOLKMER, Antonio Carlos (org). Fundamentos da História do Direito. 8 ed. Belo Horizonte (MG): Del Rey, 2014, P. 359 - 407.

34 RIBEIRO, Darcy. O Povo Brasileiro: A Formação e o Sentido do Brasil. 2 ed. São Paulo: Companhia das Letras, 1995, p. 19-20.

35 Ibidem, 1995, p. 21.
} 
introduziu novos contingentes humanos formados de europeus, árabes e asiáticos.

\section{Racismo à brasileira}

Schwarcz e Starling ${ }^{36}$ reforçam a ideia de DaMatta constante neste trabalho ao afirmar que a característica distintiva do racismo brasileiro é que ele não incide sobre a origem racial das pessoas, mas sobre a cor da pele e classe social. Há uma escala de tonalidade da epiderme que pode aproximar ou afastar a pessoa da referência étnica e social do "ser branco". No Brasil, negro é o retinto. O mulato é o pardo e como tal "meio" branco. No imaginário social e identitário características como a epiderme mais clara e a condição social mudam o pertencimento do sujeito.

Não bastasse esse arranjo social da tonalidade da epiderme para definir etnia, direitos, prerrogativas e privilégios sociais pode-se falar em uma "branquização" social ou cultural, ilustrada no fato de que negros quando ascendem socialmente, com êxito notório, passam a integrar grupos de convivência dos brancos e serem tidos como brancos. ${ }^{37}$

Isso contrasta com as opressões históricas, inclusive do ponto de vista legal que, por exemplo, colocava o negro como elemento principal do crime de vadiagem. Como fundamento à repressão da capoeira, das religiões de matrizes africanas, ao samba e demonstrações culturais. Essa situação fundamenta a constatação da falácia da democracia racial no Brasil, dada a carga de opressão, preconceito e discriminação que ela encerra, na medida que a própria expectativa de que o negro desapareça pela mestiçagem é racismo.

Conforme Schwarcz e Starling ${ }^{38}$, o Brasil é um país de tradição conservadora que buscou homogeneidades de forma impositiva para uma população heterogênea, isso é constatado nos estudos de Munanga ${ }^{39}$. Para o sucesso dessa tarefa a saída foi "esquecer" a escravidão e idealizar os indígenas, os quais,

\footnotetext{
36 SCHWARCZ, L. M. \& STARLING, H. M. Brasil: Uma Biografia. São Paulo: Editora Schwarcz S.A., 2015.

37 Ibidem, 2015.

38 Ibidem, 2015.

${ }^{39}$ MUNANGA, Kabengele. Diversidade identidade, etnicidade e cidanania. Conferência proferida no $1^{\circ}$ Seminário do III Concurso Negro de Educação. São Paulo. 21 agosto de 2003.p. 2. Disponível em http://www.acaoeducativa.org.br/fdh/wp-content/uploads/2012/09/Palestra-KabengeleDIVERSIDADEEtnicidade-Identidade-e-Cidadania.pdf. Acesso em 14 maio 2020.
} 
dizimados sistematicamente nas florestas, reapareciam em livros ${ }^{40}$ e pinturas oficiais ou semioficiais de forma romântica e mítica, infantilizada e não como sujeitos de direitos.

Dentre os muitos mitos ${ }^{41}$ presentes na sociedade brasileira, a "democracia racial", que ganhou sua elaboração acadêmica por meio de Gilberto Freyre,42 colaborou para que o racismo mantivesse mais forte permeando o tecido social brasileiro.

Apesar da consternação e choque dos postulados das doutrinas racistas americana e europeia que pregavam a inferioridade de negros e amarelos, doutrinadore ${ }^{43}$ posicionavam-se veementemente contra a miscigenação das raças e viam no Brasil um país que se implodiria devido a isso. Essa aversão à miscigenação, conforme DaMatta44, explica porque se pode falar em um "racismo à brasileira", ao lado de racismos "à europeia" e "à americana".

O conde de Gobineau 45 destacou-se ao defender a superioridade branca. Aos amarelos reserva o segundo lugar e aos negros a indigna posição de inferiores em tudo. Dessa maneira, ele teorizou um dos principais postulados das sociedades hierarquizadas pelo preconceito racial ${ }^{46}$, qual seja o de vedar o contato íntimo entre as raças/etnias, dando a pessoas e grupos o tratamento degenerado de híbridos incapazes de criar alguma coisa forte e positiva. Gobineau chegou a prever que em menos de 200 anos o Brasil se acabaria como povo, dada a permissão para miscigenação. Dessa ideia racista deriva a expressão "mulato" que provém de "mulo", utilizada por esses teóricos, para designar de forma pejorativa o animal ambíguo e híbrido por excelência, incapaz de reproduzir-se enquanto tal,

\footnotetext{
40Vide obras de José de Alencar "Iracema" e "O Guarani". No mesmo sentido as pinturas de franceses a exemplo de Jean-Baptiste Debret. População Indígena de Cantagalo 1826 e outras.

4IBERNARDINO, Joaze. Ação afirmativa e a rediscussão do mito da democracia racial no Brasil. Estud. afro-asiát., Rio de Janeiro, v. 24, n. 2, p. 247-273, 2002. Disponível em: http://www.scielo.br/scielo.php?script=sci_arttext\&pid=s0101-

546X2002000200002\&Ing=en\&nrm=iso. Acesso em: 30 março 2020.

42 FREYRE, Gilberto. Casa Grande e Senzala.

43 NINA RODRIGUES, R. de. Os africanos no Brasil, 2 ed. São Paulo: Nacional, 1935.

44 DAMATTA, Roberto. O que faz o brasil, Brasil? Rio de Janeiro: Rocco:1986, p. 38.

45 Gobineau trabalhou como cônsul da França e tornou-se amigo e interlocutor intelectual do imperador D. Pedro II. GOBINEAU. A diversidade moral e intelectual das raças, 1856.

46 Pierre-André Taguieff define preconceito racial como "juízo prematuro" que induz a que se "acredite saber sem saber, se preveja sem indícios seguros suficientes, se cheque a conclusões sem se ter as certezas necessárias" TAGUIEFF, Pierre André. La force du préjugé: essai sur le racisme et ses doublés, Paris: Editions de la Découverte, 1987, p. 233.
} 
pois resultante de um cruzamento de tipos genéticos altamente diferenciados.

O mulato é o mestiço, o misturado, isso levou a mestiçagem a uma espécie de representação nacional que foi consolidada arbitrariamente a partir de práticas violentas e da entrada forçada de povos, culturas e experiências na realidade nacional. Assim, o equívoco de compreensão das relações raciais e sociais decorre, na ótica de DaMatta47, de que "[...] o Brasil não é um país dual onde se opera somente uma lógica do dentro ou fora; do certo ou errado; do homem ou mulher; do casado ou separado; de Deus ou Diabo; do preto ou branco". Diferentes de outras regiões como nos Estados Unidos da América conforme "Antonil maravilhosamente intuiu, isto é, entre o preto e o branco (que nos sistemas anglo-saxão e sul-africano são termos exclusivos)" 48 , no Brasil há um conjunto infinito e variado de categorias que torna o racismo ainda mais difícil de ser combatido.

Com efeito, o branco colonizador, o indígena autóctone desterrado, o negro escravizado formaram uma sociedade miscigenada no que tange ao sangue, mas desconectada no que concerne às oportunidades profissionais, sociais, políticas, econômicas e jurídicas. A marginalização das raças negra e indígena permanece na vida cotidiana mantendo a sociedade brasileira desigual, negadora e até mesmo violadora de Direitos Humanos.

Reale ${ }^{49}$ ao defender a influência dos imigrantes europeus chegados no período de 1880, período do embranquecimento da população até 1933, período em que a Europa estava descentralizada política e economicamente, reforça o caráter eugênico do pensamento da época conforme se depreende da sua citação.

Ora, essa enorme massa humana era formada não de reboltalhos de raça, mas de elementos eugênicos que, se receberam como era natural a influência poderosa do meio ambiente, também reagiram sobre esse meio, inspirando novos costumes, novas maneiras de apreciar a vida, novo sentido de progresso. ${ }^{50}$

O posicionamento de Reale é contrastado de forma abalizada por Munanga quando trata da identidade negra no Brasil.

Uma história totalmente diferente da história dos emigrados europeus, árabes, judeus e orientais que, voluntariamente decidiram

\footnotetext{
47 DaMATTA, Roberto. O que faz o brasil, Brasil? Rio de Janeiro: Rocco:1986, p. 40-41.

48 Ibidem, p. 40-41.

${ }^{49}$ REALE, Miguel. Atualidades Brasileiras. 2 ed. Rio de Janeiro. Schmitd Edittor, 1937.

50 Ibidem, p. p.115.
} 
sair de seus respectivos países, de acordo com a conjuntura econômica e histórica interna e internacional que influenciaram suas decisões para emigrar. ${ }^{51}$

Nesse sentido, o New York Times 52 publicou matéria sobre como é tratada de forma dissimulada e superficial a questão do racismo no Brasil. Na prática, sob o pálio da suposta paz multicultural, a sociedade brasileira reproduz em diversos níveis os atos de racismo e intolerância religiosa com viés étnico, em relação aos negros, índios, ciganos e outras etnias consideradas por uma elite branca como de segunda categoria ou inferior. Retrata a reportagem que a população se levanta contra as ações afirmativas em prol de negros e índios sob o argumento de que a premissa das ações é falsa, pois não haveria desigualdade e racismo no Brasil.

Esse negacionismo da escravidão e seus corolários é algo articulado historicamente pelas classes dominantes, como demostra a estrofe do Hino à Proclamação da República de 1889, uma mistura de antagonismo e contradições como o de falar de altar para os símbolos da República.

Nós nem cremos que escravos outrora / Tenha havido em tão nobre País... / Hoje o rubro lampejo da aurora /Acha irmãos, não tiranos hostis. /Somos todos iguais! Ao futuro /Saberemos, unidos, levar / Nosso augusto estandarte que, puro, /Brilha, ovante, da Pátria no altar!53

Nega-se, também, que a população brasileira se originou do cruzamento de uns poucos brancos com multidões de mulheres índias e negras, pois as uniões interraciais nunca foram tidas como crime nem pecado, talvez porque o povoamento não se deu por família europeias completas, na medida que boa parte dos portugueses que aportaram no Brasil eram de degradados, pessoas com problemas financeiros, econômicos que vieram sozinhas.

A análise desse negacionismo e invisibilidade do racismo passa pelo conhecimento de suas causas, dos fatores de sua perpetuação, da atuação das

\footnotetext{
${ }^{51}$ MUNANGA, Kabengele. Diversidade identidade, etnicidade e cidanania. Conferência proferida no $1^{\circ}$ Seminário do III Concurso Negro de Educação. São Paulo. 21 agosto de 2003. p.1. Disponível em: $\quad$ http://www.acaoeducativa.org.br/fdh/wp-content/uploads/2012/09/Palestra-KabengeleDIVERSIDADEEtnicidade-Identidade-e-Cidadania.pdf. Acesso em 14 mai 2016.

52 INTERNATIONAL NEW YORK TIMES. Reportagem: Brasileiros continuam a viver em negação sobre peso do racismo na sociedade. Jornalista: Vanessa Bárbara. 24 março 2015. Disponível em: http://noticias.uol.com.br/ultimas-noticias/the-international-new-york-times/2015/03/24/emnegacao-sobre-o-racismo-no-brasil.htm. Acesso em 20 set. 2020.

53 Letra oficial no site do Palácio do Planalto. Disponível em: https://www.letras.mus.br/hinos/hinoda-proclamacao-da-republica/. Acesso em 20 set. 2020.
} 
instituições no seu combate e nas consequências para o acolhimento de migrantes que tenham origens étnicas não-brancas.

\section{O racismo institucional como política de Estado}

Na biografia do Brasil54 consta que o país foi o último a abolir a escravidão no Ocidente e continua com acentuada desigualdade social estritamente alinhada a um racismo sub-reptício e perverso. É cediço que as populações negras e pobres, sobretudo, são as que têm maiores obstáculos no acesso à educação, saúde, a cargos mais qualificados no mercado de trabalho e são mais severamente culpabilizadas pela Justiça.

No documento apresentado ao Conselho de Direitos Humanos da ONU55 pela relatora para o Direito das Minorias, Rita Izsák, há o registro que o racismo institucional continua acentuado no Brasil. Os números de afro-brasileiros que morreram como resultados de operações policiais em São Paulo são três vezes superiores aos dos registrados em relação à população branca. No Rio de Janeiro, $80 \%$ das vítimas de homicídios resultante de intervenções policiais são negras.

Isto também decorre porque a impunidade é um fator de estímulo às práticas violentas. Há ainda, de acordo com a relatora da ONU, uma "criminalização dos afro-brasileiros [...]. Estima-se que 75\% da população carcerária no Brasil seja de afro-brasileiros [...]." Estudos ainda mostram que, se condenados, afro-brasileiros são desproporcionalmente sujeitos à prisão. Os negros têm ainda mais chances de serem parados pela polícia e aqueles que são pegos com drogas, maiores chances de serem denunciados por tráfico. Izsák afirma que "desde 2005, quando as novas leis de combate às drogas entraram em vigor, o número de pessoas presas por questões relacionadas às drogas aumentou em 344\%"56. Na avaliação da relatora, a proposta de redução da idade penal de 18 para 16 anos

\footnotetext{
54SCHWARCZ, L. M. \& STARLING, H. M. Brasil: Uma Biografia. São Paulo: Editora Schwarcz S.A., 2015. 55 ONU. Rapport de la Rapporteuse spéciale sur les questions relatives aux minorités sur sa mission au Brésil. Conseil des droits de l'homme. Rita Izsák. Distr. générale 9 février 2016. Disponível em : https://www.ohchr.org/fr/NewsEvents/Pages/DisplayNews.aspx? NewsID=17233\&LanglD=FA Acesso em 02 set. 2020.

56 ONU. Rapport de la Rapporteuse spéciale sur les questions relatives aux minorités sur sa mission au Brésil. Conseil des droits de l'homme. Rita Izsák. Distr. générale 9 février 2016. Disponível em: https://www.ohchr.org/fr/NewsEvents/Pages/DisplayNews.aspx? NewsID=17233\&LanglD=FA Acesso em 02 set. 2020.
} 
perpetuaria a criminalização da comunidade afro-brasileira.

Essas constatações do relatório da ONU57 mostram que se protraíram no tempo as observações de Schwarcz e Starling de que "se na época da escravidão indivíduos negros trafegando soltos eram presos "por suspeita de escravos", hoje são detidos com base em outras alegações que lhes devolvem sempre o mesmo passado e origem". 58

Prossegue Rita Izsák59 e 60 com o argumento de que o Brasil, apesar dos avanços, tem dificuldades em lidar contra a discriminação enraizada, exclusão e pobreza, ressaltando que o mito da democracia racial é um obstáculo para se reconhecer e resolver o problema do racismo. Ressalta a relatora que a pobreza no Brasil tem uma cor de epiderme: a negra. Isto porque das 16,2 milhões de pessoas vivendo em extrema pobreza no país, 70,8\% delas são afro-brasileiras. Os salários médios dos negros são 2,4 vezes mais baixos que o dos brancos e $80 \%$ dos analfabetos brasileiros são negros. Não bastasse isso, a situação socioeconômica revela que "64\% delas não completam a educação básica", o que resulta na falta de perspectivas de futuro para os jovens negros que padecem da falta de espaços comunitários e altas taxas de evasão escolar.

A política de cotas nas instituições que detém parcela do poder não foi implantada nem no legislativo nem no Judiciário. Pelo levantamento da ONU no Judiciário, apenas $15,7 \%$ dos juízes são negros e não existe nenhum atualmente no Supremo Tribunal Federal. "No estado da Bahia, onde 76,3\% da população se identifica como afro-brasileira, apenas 9 dos 470 procuradores do Estado são afrobrasileiros", indicou. No Congresso, apenas $8,5 \%$ dos deputados são negros. ${ }^{61}$

\footnotetext{
57 ONU. Rapport de la Rapporteuse spéciale sur les questions relatives aux minorités sur sa mission au Brésil. Conseil des droits de l'homme. Rita Izsák. Distr. générale 9 février 2016. Disponível em: https://www.ohchr.org/fr/NewsEvents/Pages/DisplayNews.aspx? NewsID=17233\&LangID=FA Acesso em 02 set. 2020.

58SCHWARCZ, L. M. \& STARLING, H. M. Brasil: Uma Biografia. São Paulo: Editora Schwarcz S.A., 2015.

59 ONU. Rapport de la Rapporteuse spéciale sur les questions relatives aux minorités sur sa mission au Brésil. Conseil des droits de l'homme. Rita Izsák. Distr. générale 9 février 2016. Disponível em: https://www.ohchr.org/fr/NewsEvents/Pages/DisplayNews.aspx? NewsID=17233\&LangID=FA Acesso em 02 set. 2020.

60 ONU. Brasil: violência, pobreza e criminalização 'ainda têm cor', diz relatora da onu sobre minorias. Disponível em: https://nacoesunidas.org/brasil-violencia-pobreza-e-criminalizacao-aindatem-cor-diz-relatora-da-onu-sobre-minorias/. Acesso em 19 set. 2020.

61 ONU. Brasil: violência, pobreza e criminalização 'ainda têm cor', diz relatora da ONU sobre minorias. Disponível em: https://nacoesunidas.org/brasil-violencia-pobreza-e-criminalizacao-aindatem-cor-diz-relatora-da-onu-sobre-minorias/. Acesso em 30 março 2020.
} 
Essa violência generalizada contra os negros levou a situação de "genocídio da juventude negra". Trata-se de tragédias sociais vividas nos campos da segurança e saúde pública, que ganharam evidências devido à dimensão, profundidade e gravidade dos casos. As mortes de negros, sobretudo jovens, referem-se ao que Mbembe concebe como conceito de necropolítica aos referirse às "formas contemporâneas que subjugam a vida ao poder da morte"62.

O fato do encontro de brancos, negros e índios no Brasil não ter sido espontâneo, nem harmônico gerou uma sociedade hierarquizada dentro de um quadro rígido de valores discriminatórios, com base na legislação portuguesa que, antes mesmo da chegada dos colonizadores ao Brasil, discriminava judeus, mouros e negros.

Essa anomalia se perpetuou após a colonização, sendo a mistura de raças uma estratégia de esconder a injustiça social contra negros, índios e mulatos decorrentes das construções racistas de lhes atribui assimetrias biológicas e sociais com o branco. Portanto, é mais complicado enfrentar o racismo porque não há uma classificação racial formalizada em preto ou branco como na sociedade americana, embora com o risco de alguém com fenótipo branco ser considerado preto porque possui "sangue negro" nas veias, visto que a classificação racial, naquele país, está vinculada às origens e não apenas à cor da epiderme como é o caso brasileiro.

DaMatta63 ressalta a semelhança social entre as relações raciais no Brasil e dos Estados Unidos na época da guerra civil que marcou a luta entre o Norte igualitário e individualista que não admitia a escravidão e um Sul hierarquizado, aristocrático, com uma sociedade cheia de nuances, nessa parte, muito semelhante ao Brasil. A questão é que a sociedade brasileira não se enxerga como sistema altamente hierarquizado pelo qual a posição de negros, índios e brancos é idêntica à pregada por Gobineau e seus asseclas, pois em uma sociedade desigual o preconceito velado é a forma mais eficiente de discriminar pessoas não brancas colocando-as "nos seus devidos lugares".

Nesse diapasão, o preconceito no Brasil é muito mais contextualizado,

\footnotetext{
62 MBEMBE, Achille. Necropolítica. Biopoder, soberania, estado de exceção, política da morte. São Paulo: Edições n. 1, 2018, p. 146.

63 DAMATTA, Roberto. O que faz o brasil, Brasil? Rio de Janeiro: Rocco, 1986.
} 
sofisticado, variável, imperceptível de plano, logo, mais difícil de combater do que o americano que é direto e formal. Em suma, há "preconceito de ter preconceito", conforme sinaliza Florestan Fernandes apud DaMatta. 64

Nada obstante, ainda se acredita na construção da democracia racial no Brasil que decorre da positividade jurídica que assegura a igualdade formal perante a lei associada à mudança cultural que concede a todos a isonomia concreta, eliminando o "racismo à brasileira" "que torna a injustiça algo tolerável e a diferença uma questão de tempo e amor"65

Esse processo histórico explica porque há uma seletividade no acolhimento dos migrantes no Brasil. Pode-se inferir que o preconceito e a discriminação contra haitianos, angolanos, congoleses e outros povos africanos decorre da associação dessas pessoas aos negros escravizados que foram traficados para o Brasil, tiveram seus direitos de pessoa humana negados, foram excluídos dos ganhos econômicos e sociais mesmo após a abolição da escravatura.

Em outro giro, o tratamento desumano contra bolivianos, colombianos e paraguaios se dá em decorrência dos seus traços fenótipos associados aos indígenas brasileiros, também massacrados pelos portugueses que, apesar de nativos foram tratados como invasores ou estrangeiros no seu próprio país. Nesses dois primeiros casos, há uma associação a sentimentos de medo, impureza, risco à saúde, ou a ideia de que esses povos têm capacidade intelectual reduzida e nenhuma contribuição ao desenvolvimento econômico do país ou, ao contrário, que são espoliadores da riqueza gerada pelos brancos. Desta maneira, a burocracia estatal dificulta a obtenção de documentação para permanência e a sociedade dificulta o acolhimento, a empregabilidade e, sobretudo, a realização de Direitos e o acesso à Justiça quando necessário.

Em outro prisma, o português, branco, conseguiu manter incólume a sua representação de superioridade sobre negros e indígenas. A sua imagem está associada à pureza, às capacidades intelectual, cultural e social superiores, bem assim o perfil voltado ao empreendedorismo e ao desenvolvimento econômico. Neste ponto, o brasileiro tende a adotar uma postura de reverência, gratidão ou

\footnotetext{
64 Ibidem, 1986, p. 43.

65 Ibidem, 1986, p. 40-41.
} 
até de incondicional subserviência em relação ao imigrante branco, sobretudo, o europeu que é acolhido, ocupa os melhores empregos, desfruta de facilidades para a regularização no país, tem mais acesso a direitos fundamentos e à Justiça.

O racismo no Brasil tem ligações com o eurocentrismo, não aquele exclusivo dos europeus, mas em cada local em que está enraizado, inclusive no seio da sociedade brasileira. Isto porque em relação aos imigrantes, o tecido social ao invés de absorvê-los e incluí-los na prática, "estrangeirou alguns brasileiros ao gerar diferenciações nas áreas ou nos estratos sociais onde os imigrantes mais se concentraram", 66 com reflexos no modo de lidar com o Outro. É comum que as pessoas tratem melhor o estrangeiro americano ou europeu do que o nacional ou queiram ter sobrenomes e declarar publicamente suas origens europeia como forma de diferenciação social e privilégios ${ }^{67}$.

\section{A violência como colonizadora do "mundo da vida"}

$\mathrm{Na}$ perspectiva da tentativa de análise dos direitos dos migrantes à legislação brasileira, adequando-as à evolução dos imperativos normativos e influência nas leis nacionais, impõe-se contextualizar o fator violência no Brasil como dificultador da efetividade das normas de proteção à pessoa humana seja ela nacional ou alóctone, no contexto do mundo da vida.

O mundo da vida68 é resultado de uma rede ramificada de ações comunicativas que se difundem em espaços sociais e épocas históricas; isso porque as ações comunicativas, não somente se alimentam das fontes das tradições culturais e das ordens legítimas, como também dependem das identidades dos indivíduos socializados. Não se trata de organização na qual os membros se filiam, mas resulta do jogo entre reprodução cultural, integração social

\footnotetext{
66RIBEIRO, Darcy. O Povo Brasileiro: A Formação e o Sentido do Brasil. 2 ed. São Paulo: Companhia das Letras, 1995, p. 40.

67 REALE, Miguel. Brasil, sociedade plural. Rio de Janeiro: Expressão e cultura, 2001. Na obra, o autor questiona o que seria do Brasil sem os imigrantes europeus chegados entre 1880 e 1933, aos quais se atribui com fator primordial de formação da atual cultural nacional pois, segundo ele, "esses imigrantes traziam muita riqueza psíquica recebida no seio da família e que no final seriam responsáveis pela industrialização do país. Além disso, mostra a diferenciação entre o pensamento português atrelado ao catolicismo que prega a pobreza e os conceitos dos europeus oriundos dessa onda migratória que viam com a moral protestante, lastreada em Weber que prega a livre iniciativa e poupança sendo uma das razões determinantes do advento". (p. 28-29).

68 HABERMAS, Jürgen. Teoria da ação comunicativa. São Paulo: Martins Fontes, 2012.
} 
e socialização. Como discutido anteriormente, no Brasil essa socialização não se deu de forma pacífica, nem tão pouco dentro dos padrões éticos e com respeito aos direitos e a dignidade das pessoas.

Desde a Segunda Guerra Mundial e tirante as intervenções em missões de paz da ONU, o Brasil não se envolveu em conflitos armados nas últimas décadas. Nada obstante, o número de mortes violentas e de feridos em decorrência de atos criminosos não para de crescer, conforme demonstram os números da violência pelo país, aferidos por organizações internacionais69 ou ONG's que atuam na área.

No ranking da ONG mexicana Conselho Cidadão para a Segurança Pública e Justiça Penal, com dados de 2014,70 o Brasil tem 19 das 50 cidades mais violentas do mundo, cujo cálculo e classificação são feitos usando a taxa de número de homicídios por cada 100 mil habitantes, no universo de cidades com mais de 300 mil habitantes.

Extrai-se de essencial dos números dessa violência os perfis dos agentes causadores e das vítimas. De um lado, cresce a violência praticada por crianças e adolescentes e por agentes oficiais da ordem pública, incluindo as polícias e outras instituições similares. O Diagnóstico dos Homicídios no Brasil: Subsídios para o Pacto Nacional pela Redução de Homicídios71, elaborado pela Secretaria Nacional de Segurança Pública ao referir-se aos perfis de vulnerabilidade e vitimização no país mostra que os negros - somatória de pretos e pardos, conforme o Censo 2010 representam $50,7 \%$ da população do país e corresponderam a $72 \%$ das mortes por agressão. No caso de brancos e amarelos, o percentual é de $26 \%$.

Para o acolhimento do migrante e sua inclusão no tecido social brasileiro, necessário se faz desconstruir o mito do "homem cordial" que foi alimentado

\footnotetext{
69Dados do Mapa da Violência de 2014 mostram que em 2012 foram assinadas 56.000 pessoas no Brasil, o que equivale a $10 \%$ do total de assassinatos registrados em todo o planeta naquele ano, segundo levamento do Global Study on Homicide: Trend, contexts data de 2013 do UNODC. Disponível em https://www.unodc.org/documents/gsh/pdfs/2014_GLOBAL_HOMICIDE_BOOK_web.pdf. Acesso em 20 set. 2020.

70 CONSEJO CIUDADANO PARA LA SEGURIDAD PÚBLICA Y LA JUSTICIA PENAL A.C. Disponível em: http://www.seguridadjusticiaypaz.org.mx/biblioteca/prensa/send/6-prensa/198-las-50-ciudadesmas-violentas-del-mundo-2014. Acesso em 10 set. 2020.

71 AGÊNCIA BRASIL. Taxa de homicídios de mulheres negras é mais que o dobro da de mulheres brancas. Yara Aquino - Repórter da Agência Brasil. Publicado: 16/10/2015. Disponível em: http://agenciabrasil.ebc.com.br/direitos-humanos/noticia/2015-10/homicidios-de-mulheresnegras-sao-mais-que-o-dobro-de-mulheres. Acesso em 10 set. 2020.
} 
durante anos em distorção ao real sentido proposto por Holanda ${ }^{72}$. Para o autor, o termo cordial, em certa medida, significa privilegiar a emoção em detrimento da razão, não fazer distinção entre o privado e o público, rejeitar formalidades necessárias ao convívio social e sobrepujar o comportamento ético e os postulados mínimos de civilidade.

Essa temática foi retomada por DaMatta73 na metáfora da "casa" e da "rua", que ilustra a divisão entre esses dois espaços sociais fundamentais, onde se englobam teoricamente o trabalho, o movimento, a surpresa e a tentação, indicando vestígios de como são tratadas as questões sociais, econômicas, a criação e aplicação das leis no país. A "casa" e a "rua" são mais que espaços físicos delimitados, são perspectivas de leitura e interpretação, opostas mas complementares. A casa no sentido da vida como um "fato social totalizante" e um "espaço totalizado" na moral, pois o sujeito é membro de uma família e de um grupo social com limites bem definidos.

DaMatta considera que no Brasil, na vertente inclusiva, tudo que for material e físico pertence à casa. Homens, mulheres e crianças também. Acrescente-se a isso os serviçais cujas vidas parecem pertencer aos patrões, aliás, uma característica marcante da sociedade brasileira.

O autor aponta a complexidade da relação da casa e da rua mediada pelo trabalho, pois o trabalhador não é glorificado nem tampouco existe a confiança que se possa ganhar dinheiro ou enriquecer honestamente e relaciona esse fato à formação da sociedade brasileira quando "o patrão, num sistema escravocrata, é mais que um explorador de trabalho, sendo dono e até mesmo responsável moral pelo escravo. ${ }^{74}$

O exemplo clássico dessa complexidade se refere às empregadas domésticas cuja relação de trabalho com os seus patrões possui características semelhantes aquelas do tempo da escravidão. Há então uma confusão nas relações morais de intimidade e simpatia com um vínculo puramente econômico, criando um conjunto de dramas pela mistura entre o moral e o político, em uma palavra entre a "casa" e a "rua" como espaços onde se pode "julgar, classificar,

\footnotetext{
72 HOLANDA Sérgio Buarque de. Raízes do Brasil. São Paulo: Companhia das Letras, 2015.

73 DaMATTA, Roberto. O que faz o brasil, Brasile Rio de Janeiro: Rocco:1986, p.23-33.

74 Ibidem, 1986, p.32.
} 
medir, avaliar e decidir sobre ações, pessoas, relações e moralidades. "75

No horizonte do tratamento do migrante no Brasil essas questões vêm à tona sob a forma de alguns exemplos. No caso dos bolivianos, há a exploração escravocrata da sua mão-de-obra em fábricas de tecidos e outros empreendimentos nas metrópoles, bem assim na contratação de empregadas domésticas que são chamadas a substituir o trabalho doméstico, antes das mulheres negras brasileiras, que começam a conquistar direitos laborais.

Em se tratando de haitianos, por exemplo, as tensões raciais, os preconceitos e discriminações os alcançam na medida que Ihes são reservados subempregos ou atividades de baixa remuneração, devido à cor da epiderme e à origem pobre. Dessa forma, embora os brasileiros de uma forma geral adotem posturas em redes sociais, compartilhando apelos pela igualdade, solidariedade e respeito aos Direitos Humanos de imigrantes no continente europeu, internamente se referem a esses oriundos das migrações Sul-Sul com sendo ameaças aos seus empregos e aos sistemas de saúde e educação comprometidos pela ineficácia e corrupção endêmica que assola o país.

Sorj76 aborda o tema da existência de uma classe média alienada pelo consumo, embevecida pela detenção de privilégios, mas pouco receptiva para o cumprimento de deveres ou para as limitações administrativas e sociais necessárias para convivência harmônica em sociedade.

Em concordância com Almeida77, O racismo está subjacente e institucionalizado no imaginário nacional brasileiro, porque em muitos estudos e até mesmo no marco legal, a desigualdade racial foi utilizada para justificar a inferioridade negra, não fazendo críticas sobre a condição das pessoas na perspectiva da dignidade humana. De forma complementar, Mbembe ${ }^{78}$ reforça os equívocos cometidos por pesquisadores ao afirmaram que os negros americanos eram mais evoluídos do que os africanos porque tiveram mais contato com os brancos. Portanto, foi no colonialismo que a racionalização da raça passou

\footnotetext{
75 Ibidem, 1986, p. 33.

76 SORJ, Bernardo. A Democracia inesperada: cidadania, direitos humanos e desigualdade social. Rio de Janeiro: Jorge Zahar Ed. 2004.

77 ALMEIDA, Silvio Luiz de. O que é racismo estrutural? Belo Horizonte (MG): Letramento, 2018.

78 MBEMBE, Achille. Necropolítica. Biopoder, soberania, estado de exceção, política da morte. São Paulo: Edições n. 1, 2018
} 
a servir como fundamento de dominação. "O Estado age em constante estado de exceção e estado de sítio, reproduzindo guerra, homicídio, políticas de repressão e suicídio ${ }^{79}$.

\section{Considerações finais}

Considerando o Brasil um país composto por migrantes, o racismo prevalece por aqui por diversas razões, como discutidas nesse trabalho. Na seara das liberdades individuais e coletivas, que precisam ser asseguradas em uma legislação migratória, o aspecto da colonização e da incipiente redemocratização do país e suas consequências nos diversos domínios do "mundo da vida".

Constata-se nas relações entre as classes e no estabelecimento de geografias de poder e privilégios são necessárias ações para a formação de um conjunto normativo realmente pautado em Direitos Humanos, visto que a índole autoritária do país reflete nessas construções. Desde o legado autoritário, genocida e escravagista, o Brasil mantém suas dicotomias na forma de lidar com pessoas e grupos, provocando choques entre os direitos fundamentais não equivalentes a cidadãos e categorias, a manutenção de castas sociais, além de nichos de desigualdades difíceis de serem revertidos.

Portanto a gênese do racismo, subjacente às legislações, mitos e costumes pretéritos continua a se reproduzir configurando o racismo estrutural, quando as situações se mantêm presas a processos históricos de controle de "uns" sobre os "outros" inventariados nos encontros coloniais e na necessidade de construir epistemologias descolonizadas, em diferentes dimensões dos conflitos étnicos/raciais com vistas à compreender o processo do racismo à brasileira.

Essa ideia remeta à de democracia racial que se disseminou, mantendo enraizado um imaginário perverso de superioridade e inferioridade, que leva a negação do racismo e faz prevalecer a manutenção da desigualdade entre brancos e negros.

Cabe viver pertencimentos nas representações históricas e na construção de identidades que se pautam em epistemologias descolonizadoras para provocar a

${ }^{79}$ ALMEIDA, Silvio Luiz de. O que é racismo estrutural? Belo Horizonte (MG): Letramento, 201, p. 90. 
ruptura e mudança de perspectiva, com vistas à pluralidade humana, considerando um Brasil de todas as cores e de tantos amores, quando se remete à pergunta feita por Spivak80 na epígrafe desse texto: pode o subalterno falar?

\section{Referências}

AGÊNCIA BRASIL. Taxa de homicídios de mulheres negras é mais que o dobro da de mulheres brancas. Yara Aquino. Publicado: 16/10/2015. Disponível em: http://agenciabrasil.ebc.com.br/direitos-humanos/noticia/2015-10/homicidios-demulheres-negras-sao-mais-que-o-dobro-de-mulheres. Acesso em 10 set. 2020.

AGÊNCIA BRASIL. Europeus consideram Brasil uma potência, diz Durão Barroso. Renata Giraldi. Disponível em: http://agenciabrasil.ebc.com.br/noticia/2011-1004/europeus-consideram-brasil-uma-potencia-diz-durao-barroso. Acesso em 05 set. 2020

ALMEIDA, Silvio Luiz de. O que é racismo estrutural? Belo Horizonte (MG): Letramento, 2018.

BERNARDINO, Joaze. Ação afirmativa e a rediscussão do mito da democracia racial no Brasil. Estud. afro-asiát., Rio de Janeiro, v. 24, n. 2, p. 247-273, 2002. Disponível em: http://www.scielo.br/scielo.php?script=sci_arttext\&pid=s0101546X2002000200002\&lng=en\&nrm=iso. Acesso em: 30 março 2020.

BRASIL. Lei 581 de 04 de setembro de 1850. Disponível em: http://www.planalto.gov.br/ccivil_03/LEIS/LIM/LIM581.htm Acesso em 05 set. 2020.

BRASIL. Lei 2040 de 28 de setembro de 1781. Disponível em: http://www.planalto.gov.br/ccivil 03/leis/lim/lim2040.htm Acesso em 20 set. 2020.

BRASIL. Lei n. 3270, de 28 de setembro de 1885. Disponível em: https://www.bn.gov.br/explore/curiosidades/28-setembro-1885-promulgadalei-sexagenarios. Acesso em 21 set. 2020

BRASIL. Letra oficial no site do Palácio do Planalto. Disponível em: https://www.letras.mus.br/hinos/hino-da-proclamacao-da-republica/. Acesso em 20 set. 2020 .

BRASIL. Lei 3.353, de 13 de maio de 1888. Disponível em: http://www.planalto.gov.br/ccivil 03/leis/lim/LIM3353.htm Acesso em 21 set. 2020.

BULA ROMANUS PONTIFEX. Disponível em: http://www.baciadasalmas.com/bula-

${ }^{80}$ SPIVAK, Gayati Chakravorty. Pode o subalterno falar? Tradução Sandra Regina Goulart Almeida, MARCOS Pereira Feitosa e André Pereira Feitosa. Belo Horizonte: UFMG, 2010 
romanus-pontifex/. Acesso em 05. fev. 2016.

CHAUI, Marilena. Brasil: Mito Fundador e Sociedade Autoritária, São Paulo: Fundação Perseu Abramo, 2000.

CONSEJO CIUDADANO PARA LA SEGURIDAD PÚBLICA Y LA JUSTICIA PENAL A.C. Disponível em: http://www.seguridadjusticiaypaz.org.mx/biblioteca/prensa/send/6-prensa/198las-50-ciudades-mas-violentas-del-mundo-2014. Acesso 10 set. 2020.

DAMATTA, Roberto. O que faz o brasil, Brasil? Rio de Janeiro: Rocco:1986.

FERNANDES, Florestan. A Integração do Negro à Sociedade de Classes. São Paulo, FFLCH-USP, 1964In: Macedo Soares, 1939, p. 25-8.

FERRAJOLI, Luigi. A Soberania no mundo moderno. São Paulo: Martins Fontes. 2002.

FREYRE, Gilberto. Casa Grande \& Senzala: formação da família brasileira sob regime da economia patriarcal. 49 ed. São Paulo: Global, 2004.

GOBINEAU, J. A diversidade moral e intelectual das raças, 1856.

HABERMAS, Jürgen. Teoria da ação comunicativa. São Paulo: Martins Fontes, 2012.

HOLANDA, Sérgio Buarque de. Raízes do Brasil. São Paulo: Companhia das Letras, 2015.

NEW YORK TIMES. Reportagem: Brasileiros continuam a viver em negação sobre peso do racismo na sociedade. Jornalista: Vanessa Bárbara. 24 março 2015. Disponivel em: http://noticias.uol.com.br/ultimas-noticias/the-international-newyork-times/2015/03/24/em-negacao-sobre-o-racismo-no-brasil.htm. Acesso em 20 set. 2020.

MBEMBE, Achille. Necropolítica. Biopoder, soberania, estado de exceção, política da morte. São Paulo: Edições n. 1, 2018, p. 146.

MUNANGA, Kabengele. Diversidade identidade, etnicidade e cidanania. Conferência proferida no $1^{\circ}$ Seminário do III Concurso Negro de Educação. São Paulo. 21 agosto de 2003.p. 2. Disponível em http://www.acaoeducativa.org.br/fdh/wp-content/uploads/2012/09/PalestraKabengele-DIVERSIDADEEtnicidade-Identidade-e-Cidadania.pdf. Acesso em 14 maio 2020.

NASCIMENTO, W. e PEREIRA, M. S. Desafios de Pesquisar os "Outros" em Contextos Coloniais Africanos. In: Santana, M.; Ferreira, E.; Nascimento, W. Luanda \& Bahia: identidades e etnicidades em contextos contemporâneos. Campinas, SP: Pontes 
Editores, 2020.

NINA RODRIGUES, R. de. Os africanos no Brasil, 2 ed. São Paulo: Nacional, 1935.

O GLOBO. Papa pede desculpas a indígenas por cumplicidade da Igreja durante era colonial. Disponível em: http://oglobo.globo.com/sociedade/religiao/papapede-desculpas-indigenas-por-cumplicidade-da-igreja-durante-era-colonial16722556\#ixzz3yp89Y2yn. Acesso em 5 set. 2020.

ONU. Rapport de la Rapporteuse spéciale sur les questions relatives aux minorités sur sa mission au Brésil. Conseil des droits de l'homme. Rita Izsák. Distr. générale 9 février 2016.

Disponível

em:

https://www.ohchr.org/fr/NewsEvents/Pages/DisplayNews.aspx? NewsID=17233\&La nglD=FA . Acesso em 02 set. 2020.

PEREIRA, João Baptista Borges. Diversidade e pluralidade: o negro na sociedade brasileira. Rev. USP, São Paulo, n. 89, maio 2011. Disponível em http://rusp.scielo.br/scielo.php? script=sci_arttext\&pid=S0103-

99892011000200019\&lng=pt\&nrm=iso. Acessos em 21 set. 2020.

REALE, Miguel. Atualidades Brasileiras. 2 ed. Rio de Janeiro. Schmitd Edittor, 1937.

RIBEIRO, Darcy. O Povo Brasileiro: A Formação e o Sentido do Brasil. 2 ed. São Paulo: Companhia das Letras, 1995.

SCHWARCZ, L. M. \& STARLING, H. M. Brasil: Uma Biografia. São Paulo: Schwarcz S.A., 2015.

SCHWARTZ, Stuart B. Segredos Internos: engenhos e escravos na sociedade colonial (1550-1835). São Paulo: Companhia das Letras, 1988.

SILVA FILHO, José Carlos Moreira. Da "invasão" aos sistemas penais de hoje: o discurso da inferioridade latino-americana. In: WOLKMER, Antônio Carlos (org). Fundamentos da História do Direito. 8 ed. Belo Horizonte (MG): Del Rey, 2014, p. 359 $-407$.

SPIVAK, Gayati Chakravorty. Pode o subalterno falar? Tradução Sandra Regina Goulart Almeida, MARCOS Pereira Feitosa e André Pereira Feitosa. Belo Horizonte: UFMG, 2010.

SOARES, Luiz Carlos. O "povo de Cam" na capital do Brasil: A escravidão Urbana no Século XIX: Rio de Janeiro: 7 letras, 2007.

SORJ, Bernardo. A Democracia inesperada: cidadania, direitos humanos e desigualdade social. Rio de Janeiro: Jorge Zahar Ed. 2004. 
TAGUIEFF, Pierre André. La force du préjugé: essai sur le racisme et ses doublés, Paris: Editions de la Découverte, 1987.

TODOROV, Tzvetan. A conquista da América: a questão do outro. 3 ed. São Paulo: Martins Fontes, 1993.

UNODC. Dados do Mapa da Violência de 2014. Levamento do Global Study on Homicide: Trend, contexts data de 2013 do UNODC. Disponível em: https://www.unodc.org/documents/gsh/pdfs/2014_GLOBAL_HOMICIDE_BOOK_we b.pdf. Acesso em 20 set. 2020.

Claudia de Faria Barbosa: Doutora e Mestra no Programa em Família na Sociedade Contemporânea (UCSAL), cuja tese recebeu menção honrosa pela originalidade e ineditismo na abordagem. Especialista em Administração e Desenvolvimento de Pessoas (Fundação Visconde de Cairu), Políticas Públicas (UNEB) e Metodologia do Ensino, Pesquisa e Extensão (UNEB). Graduada em Pedagogia - (UCSAL), Secretariado Executivo (UFBA) e Direito (incompleto). Possui créditos nos PPGs stricto sensu em Educação e Contemporaneidade - (UNEB) e em Estudos Interdisciplinares sobre Mulheres, Gênero e Feminismo (UFBA).

Clodoaldo Silva da Anunciação: Doutor em Direito pela Université Paris 1 Panthéon Sorbonne em cotutela e dupla diplomação com a Universidade de São Paulo (USP), mestre em Direito pela Universidade Federal da Bahia. Professor Adjunto na Universidade Estadual de Santa Cruz (UESC), Vice-líder do grupo de Pesquisa Observatório das Migrações do Estado da Bahia (UESC). Pesquisador do Grupo de Pesquisa em Direitos Humanos e Fundamentais- GPDH (UESC). Promotor de Justiça no Ministério Público do Estado da Bahia, Idealizador do programa \&quot; O MP e os Objetivos do Milênio: Saúde e Educação de Qualidade para Todos, ganhador do prêmio de Melhor Projeto na categoria de Defesa dos Direitos Fundamentais do Conselho Nacional do Ministério Público (CNMP, 2013) e menção honrosa do Prêmio Innovare (2014).

(9) (1)

This work is licensed under a Creative Commons Attribution 4.0 International License.

Este trabalho está licenciado com uma Licença Creative Commons - Atribuicão 4.0 Internacional.

Artigo recebido para publicação em: 01 de outubro de 2020.

Artigo aprovado para publicação em: 03 de novembro de 2020. 